\title{
The Royal Aberdeen Children's Hospital: 'Hospital of the year 1989'
}

\author{
G Russell
}

In 1929 the Royal Aberdeen Hospital for Sick Children moved from a cramped Victorian building in the city centre to a new hospital on a greenfield site in the suburbs, constructed in the then fashionable pavilion style with tiny wards whose glass fronted verandas entrained draughts more often than they caught the sun. Linked by endless corridors, these wards which were 'lightly built to last for thirty years or so' remain the nucleus of the present Royal Aberdeen Children's Hospital, which has been awarded the accolades 'Best teaching hospital' and 'Hospital of the year' in the Sunday Times Best of Health Competition for 1989.

This competition between NHS hospital managers 'to find Britain's finest hospitals' attracted 212 entries, the diversity of which was reflected in the submissions reaching the final round. The entry from Argyle and Bute Hospital described a five year plan to improve the quality of life for its psychiatric inpatients, the development of a community outreach programme, and the stimulating effects of an active teaching and research programme. Bolingbroke Hospital reported a quality initiative in a geriatric inpatient unit, with changes including new uniform design, the reintroduction of the post of 'matron' (who says we can't learn from the past?) and the daily hoisting of the hospital flag. The submission from the Royal Earlswood Hospital described the interaction between hospital and community in a mental handicap hospital, and that from Withybush Hospital described the impact of an 'Aspiring to excellence' programme on the care of patients in a district general hospital and the community it serves. The winning Aberdeen submission described the organisation development initiative and the quality enhancement programme which were central to the introduction of general management in the maternity and child health unit.

The Griffiths report was implemented late in Scotland and a general manager was appointed to our unit only in 1987 . He came from a nonmedical services background and his plan of campaign was awaited with some trepidation. In the event, the nearest military analogy was that of the 'hundred days,' spent not in frenetic activity culminating in disaster but in listening, observing, and evaluating; the frenetic activity was to come later and the disaster (fingers crossed) has yet to appear.

An early product of general management in Grampian was the establishment, with the help of management consultants, of an organisation development initiative, designed to resolve numerous problems identified in questionnaires completed by over 1000 staff members from all grades in all disciplines. The problem list included poor internal communications, a defensive management style, resistance to change, the lack of a cohesive strategy, and a planning process that was opaque and secretive. These and other deficiencies were tackled by holding regular management briefings and seminars, by appointing a 'change agent' with specific responsibility for promoting innovation, by inviting a clinician, with the help of senior medical, nursing, and paramedical staff, to write a 10 year strategic plan for the hospital, and by appointing a clinician to a part time management role as 'clinical services coordinator' (that's me, folks). Two years later a repeat survey showed that the staff now felt much less isolated from management and that they belonged to an organisation that was (in the optimistic words of one of the questions) 'going places', even if (after the white paper) no-one knew quite where.

As elsewhere in the acute sector, it was departmental policy that developments had to be paid for by efficiency savings. The first task of this 'new improved' management team was therefore to develop a strategy that would generate savings to pay for essential developments. Substantial savings resulted from competitive tendering (the in house team beat all comers), energy saving and so forth, but our area of greatest inefficiency lay in a permanantly low bed occupancy. This was addressed by a team of clinicians chaired by the manager, and the results of our deliberations radically altered the disposition of our patient and parent accommodation.

The Children's Hospital had long been proud of its mother and baby unit, the first purpose built unit of its kind in the UK, opened in 1950 after a devastating epidemic of infantile gastroenteritis two years previously. Designed to allow hospitalised babies the protective effect of breast feeding, the unit had declined in popularity over the years, and attempts to resurrect it were never entirely successful. The function of the unit was therefore changed from that of a fully staffed ward for 12 parent-child pairs to a hostel staffed by a part time receptionist and catering for 24 parents. The demand for this accommodation is now almost insatiable.

Surgical activity was shared between three wards, two of which were consistently under utilised. A small dermatology ward was con- 
verted into an accident and emergency ward; this in turn allowed one surgical ward to be converted into a combined adolescent and dermatology unit incorporating outpatient facilities. These and other changes, while far from painless, freed resources for a multiplicity of developments.

An obvious starting point was the front door, flanked on one side by a bleakly uninviting waiting area and on the other by the records department, and unmarked as if we were ashamed of the very existence of the hospital. The patient waiting area was extended and converted into a carpeted and attractively furnished cafe and shop run by the Women's Voluntary Service and now an important source of income generation. The records department, so often a family's first and last point of contact with the hospital, was dingy and uninviting. Opened 25 years previously (before then, we kept records in shoe boxes obtained from the orthopaedic bootmaker), it had proved less adequate for modern requirements than had the shoe boxes of a former era. It was extended to provide a vastly improved working environment for the staff and an attractive reception and appointments area for families. Finally, the hospital's name was proudly emblazoned over the door; we had something to be proud of.

The 'shop window' of any hospital is the accident and emergency department. Here children waiting for routine clinic appointments were subjected to the sights and sounds associated with the arrival of children with major trauma, sudden death, and the like; a new ambulance entrance and some revision of the internal partitions solved this problem. A family room with homely furnishings was provided for the use of anxious and grieving parents and has been greatly appreciated.

Like many hospitals we were well endowed with corridors. Ours were narrow, low and echoing, usually with a chill wind whistling through them. Automatic doors cured the chill winds, pictures by the children broke up the long low lines, and carpets removed the echo and added to the 'deinstitutionalisation' which had been indentified as a important priority.

These and numerous other changes improved the facilities for patients, but what of the staff? Our dining room was unattractive, the servery impossibly congested, and the coffee lounge impenetrably polluted with tobacco smoke. The doctors' dining room, the last relic of a former elitist era, was taken over as the hospital's only smoking area for staff (thereby ensuring that piqued doctors made no attempt to recapture their lost territory), a new servery was created, and the dining room and coffee lounge were carpeted and refurbished. The food, always good, now seemed even better when taken in surroundings more reminiscent of a fashionable restaurant than a hospital canteen. To some, this was a diversion of funds from direct patient care, but to most it indicated that at long last the NHS was prepared to look after its staff. Our Napoleon realised that an army marches on its stomach!

The medical staff felt that previous administrations had been blind to their needs. Some three dozen consultants shared a single office and were serviced by a typing pool, the quality of which was largely dependent on the efforts of one august lady whose association with the hospital antedated the NHS. A long abandoned isolation unit, used for the storage of $\mathbf{4 0}$ year old obstetrical records, the steriliser from a long defunct milk kitchen, a Bird Mark 8 ventilator held together with sticky tape, and other hospital bric a brac, was converted to a department of medical paediatrics with individual consultant offices and, perhaps more important, personal secretaries. A similar facility was provided for the paediatric surgeons.

These organisational and structural changes, however beneficial, were not in themselves the reason for our success in the competition. We were asked quite specifically what we meant by quality, how we evaluated it, and how consumer opinion was tested. The organisation development initiative had recommended the appointment of a quality assurance officer to provide training (in the first year, $50 \%$ of staff attended customer care seminars), advise on standard setting, and help staff to develop appropriate quality assurance initiatives. Two examples reveal the value of this formalised approach to quality:

(1) On the wards, a nursing working party developed quality evaluation of standards (QUEST) to monitor the planning and delivery of patient care and to evaluate physical conditions on the ward. This tool has proved invaluable not only in setting and maintaining standards of family care, but as a planning tool indicating where money might best be spent to improve quality.

(2) Throughout the hospital prominence is given to complaint and suggestion cards, all of which are investigated by the appropriate member of the unit management team. Predictably, this practice of 'touting' for complaints did not meet with universal approval. Most complaints concern poor organisation or physical conditions, both of which are clearly amenable to management action; we receive few complaints about individual staff members. Although we continue to receive complaints, action taken on previous complaints has ensured that the number is diminishing. Towards the end of 1989 a major consumer survey was undertaken in which 814 parents returned cards; only one seriously adverse comment was made.

The impact of these changes on clinical care is difficult to quantify, but the clear definition of a child and family centred hospital philosophy, the emphasis on 'customer care', the flexible approach of management, and the increased readiness of staff to accept change, combined with physical improvements of the type described above, have inevitably had a favourable impact on clinical practice. One simple example of this increased willingness to accept change is that our nurses, after decades of refusal, are now prepared to give intravenous injections.

Are there general lessons to be learned from our experience? Brian Deer of the Sunday Times said that 'quality is all about having choice, comfort and respect'. In our remote northern fastness, we cannot offer our patients a choice of hospital, or even much choice within the hospi- 
tal, and we certainly didn't win the competition by doing so. Many of the physical changes we made to the hospital were designed specifically to improve patient comfort, but I doubt if that either had much to do with winning the competition. What management has achieved is two important changes in attitude. Firstly, change is now seen as an integral part of hospital culture; closing the mother and baby unit was tantamount to slaughtering the sacred cow, but in the end attracted few complaints and an unsuccessful attempt to get up a petition. Secondly, technical excellence is no longer enough; patients are seen as clients whose custom we value and whose views we respect. These changes in attitude will continue to bear fruit long after the elation of winning the Sunday Times competition has evaporated.

Finally, for the sake of accuracy, I should point out that our Napoleon was in reality from the Royal Air Force; try as I might, I could not incorporate Biggles in this essay. The Napoleonic analogy continues; after his success in 'turning round' the Children's Hospital, he has been exiled to solve some little local difficulties in our mental hospital! 